\title{
El rol de los medios de comunicación en la construcción de discursos en la "guerra contra la delincuencia juvenil” en Chile (1990-2016)
}

\author{
Alejandro Tsukame Sáez \\ Universidad Academia de Humanismo Cristiano, Santiago, Chile. \\ Email: avtsukame@yahoo.es
}

Resumen: La discusión del tema del delito de menores en los medios de comunicación, entre los años noventa y hasta la segunda década de los dos mil, gira en torno al tema de la seguridad ciudadana y a la necesidad de políticas de tolerancia cero con la delincuencia juvenil. Los medios no inventan la realidad, pero la reproducen y amplían con impactante eficacia. El particular tratamiento que los medios hacen de la delincuencia de los menores, construye la imagen ideológica de un sujeto marginal, ensaya la implementación de novedosas tecnologías de poder, contribuye a revelar la forma como opera el actual campo de control de la delincuencia de los menores en Chile y constituye una demostración tangible de los efectos regresivos de dichas políticas en los procesos de participación y profundización de la democracia en Chile.

Palabras clave: Delincuencia juvenil, ideologías y tecnologías de poder, medios de comunicación, seguridad ciudadana, tolerancia cero.

\section{The role of the media in the construction of discourses on the "war against juvenile delinquency" in Chile (1990-2016)}

Abstract: The discussion in the media about crime done by minors, between the years ninety until the second decade of the two thousand, spins around the theme of citizen security and the need of a zero tolerance politics with juvenile delinquency. The media do not invent reality, but reproduce and amplify with impressive efficiency. The particular treatment the media make on minors delinquency, builds the ideological image of a marginal subject, rehearses the implementation of innovative technologies of power, contributes to reveal the form in which operates the current control field of juvenile delinquency in Chile and is a tangible demonstration of the regressive effects of these policies in the processes of participation and democracy in Chile.

Keywords: Juvenile delinquency, ideologies and technologies of power, media, citizen security, zero tolerance.

\section{O papel da mídia na construção de discursos na "guerra contra a delinquência juvenil” no Chile (1990-2016)}

Resumo: A discussão sobre a questão da criminalidade juvenil na mídia, 
incluindo os anos noventa e até a segunda década dos anos dois mil, gira em torno da questão da segurança pública e da necessidade de políticas de tolerância zero em matéria de criminalida de juventude. Os meios de comunicação não inventam a realidade, mas a reproduzem e expandem com impressionante eficácia. O tratamento especial, que os meios de comunicação fazem da delinquência juvenil, constrói a imagem ideológica de um sujeito marginal, ensaia a implementação de tecnologias inovadoras de energia, ajuda a revelar a forma como opera o atual campo de controle da criminalidade de menores no Chile e constitui uma demonstração tangível dos efeitos regressivos de tais políticas nos processos de participação e aprofundamento da democracia no Chile.

Palavras-chave: delinquência juvenil, ideologias e tecnologias de poder, mídia, segurança pública, tolerância zero.

$* * *$

\section{Introducción: La delincuencia de menores y la seguridad ciudadana en los años noventa y dos mil}

En un lúcido y valiente libro, titulado "La Guerra y la Paz Ciudadana”, los periodistas Juan Guzmán y Marcela Ramos denunciaron, a fines de los años noventa, las consecuencias de la guerra que se había declarado contra la delincuencia en nombre de la seguridad ciudadana: Debajo de lo que hemos entendido como la guerra contra los delincuentes se ha amontonado un enorme desastre social; también un negocio de proporciones y, sobre todo, una nueva forma de ordenar nuestra convivencia, de distribuir derechos, valoraciones morales, acceso a los espacios públicos(Guzmán y Ramos 2000: 9 - 10). El nombre del libro apunta directamente a la Fundación Paz Ciudadana, creada por el dueño del Diario El Mercurio, Agustín Edwards en 1992.

En 1991, luego del asesinato del senador de la UDI, Jaime Guzmán y el secuestro de Cristián Edwards, hijo de Agustín Edwards, la derecha y los empresarios se sintieron vulnerables como no lo estaban desde los días de la Unidad Popular. La sensación de amenaza fue avalada por el primer gobierno democrático después de la dictadura, que vio en la pervivencia de grupos que favorecían la lucha armada, el peligro de lo que llamaron una “colombianización” de la transición a la democracia. La moderación se impuso como estilo político en los inicios de este primer gobierno, que parecía a ratos pedir permiso para gobernar y ocupar los cargos. Desde el mismo día en que se produjo la asunción del gobierno democrático, un desconfiado traspaso de espacios de poder entre los militares y civiles que gobernaban con Pinochet y los nuevos grupos que representaban los anhelos de millones de personas, recordaba que la democracia pendía de un hilo.

El día 3 de abril de 1992, en el Centro de Extensión de la Universidad Católica de Chile, Agustín Edwards anunció la creación de la Fundación Paz Ciudadana, cuya influencia en los años venideros colmaría la agenda política en las temáticas de seguridad y justicia. En su directorio figuraban altos dirigentes políticos de derecha e izquierda, -más de derecha que de izquier- 
da, en realidad- y poderosos empresarios. Durante todo el año 1992, una seguidilla de editoriales del diario el Mercurio, denunciaba el desarrollo de un sentimiento de inseguridad en la población, "con algunas ideas fuerza, como que el fenómeno de la delincuencia se inicia con la democracia; relacionar la ineficiencia policial con el discurso de los derechos humanos y hablar con sorna de los 'derechos de los delincuentes'; personificar al terrorista y luego al delincuente como un ente con 'mentalidad asesina'; atribuir el problema a una 'falta de temor' del delincuente, por lo que la solución es el castigo o la amenaza de castigo" (Hoecker 2000: 35)

La violencia, en sus diversas formas, fue el tema de fondo de los primeros años de democracia. La violencia política del terrorismo de Estado, nuevamente recreada con la apertura de numerosas causas de derechos humanos y la violencia terrorista, fueron los temas más visibles. El discurso sobre la inseguridad influyó en forma natural en las clases medias, en relación con experiencias de precariedad social y personal, desde el inicio mismo de la transición a la democracia. La "delincuencia juvenil” se presentaba en simultáneo como una delincuencia depredadora y violenta y ayudó a que las imágenes del terrorista y el delincuente se mezclaran sin mayores problemas. Cuando las políticas gubernamentales implementadas hicieron desaparecer al primero, la delincuencia de los menores de edad pasó a llenar ese vacío. Pero, también se hizo notar la violencia de las relaciones sociales en ámbitos no asumidos con anterioridad, como la discriminación en las escuelas, la violencia doméstica, el maltrato en las relaciones laborales, la violencia entre vecinos, el maltrato infantil. El mismo año 1990, la muerte de un adolescente de 15 años, a manos de otro de la misma edad en un barrio marginal de Santiago, sirvió en los medios como botón de muestra de la peligrosidad de los delincuentes juveniles: "Frente al porfiado e inexplicable intento de algunos para disminuir la gravedad de la delincuencia juvenil, surgió ayer el asesinato de un niño de 15 años... pero el dato esencial de este horroroso episodio es que el autor material del asesinato tiene también quince años, como su víctima (...) ¿Podrá quedar relegada $a$ un segundo plano la lucha frontal contra la delincuencia, que requiere prioridad y recursos humanos y materiales $?^{1}$. Tres años después, la violencia tocaba también a las “pandillas” juveniles. Una riña que terminó con la vida de una mujer, ajena a los hechos, involucró a miembros del grupo juvenil "Malas Juntas”, que se enfrentaron al grupo "CNI”, adversarios en la calle y en el rap. Hasta ese momento, dichos grupos eran conocidos solo por causar desórdenes y beber alcohol, pero el hecho fue difundido bajo títulos como "Pandilleros aterrorizan a San Miguel" y "Delincuentes juveniles están fuera de control”. En 1998, una riña similar afectó al grupo "Los Vatos Locos", resultando muerto un niño de 15 años al interior de una vivienda. Los "Vatos Locos" fueron portada en los diarios y generaron debate por casi un mes: "Probablemente porque los hechos ocurrieron dentro de los límites de una comuna acomodada de Santiago y porque el autor del homicidio fue declarado sin discernimiento por la Corte de Apelaciones de Santiago”(Guzmán y Ramos 2000: 164). 
Los hechos anteriores, leídos como irrupción de una delincuencia de menores violenta e "irresponsable”, adelantaban la discusión que se haría sentido común en la década del 2000: un persistente alegato por la ineficacia del sistema del discernimiento, característico de la justicia tutelar de menores vigente, que al considerar irresponsables a los menores de edad por sus delitos, los deja en la impunidad. Esta idea se reforzaba con la publicación de cifras que mostraban que la delincuencia juvenil estaba "fuera de control”. En 2002 un estudio de la Fundación Paz Ciudadana titulado: "Delincuencia juvenil en Chile: tendencias y desafíos", destacaba un aumento de cerca de $400 \%$ en las detenciones por "delitos de mayor connotación social” (robos, hurtos, lesiones, violación, violencia intrafamiliar) entre 1996 y 2002, tanto en adultos como en menores, si bien las detenciones de menores lo hicieron en una menor proporción: 398\% contra 436\% en adultos.

En el cambio de siglo, se había acuñado la imagen de un enemigo frontal en la figura de un delincuente cada vez más próximo a una condición de niño, listo para atacar con una violencia creciente, apoyado en una pandilla igualmente salvaje, desertor escolar, y que no trabaja o lo hace muy esporádicamente. El editorial de un diario santiaguino, hacía extensiva esta condición a toda la generación de los 90, con el título de "juventud agresiva” y agregaba: "La combinación entre agresividad e indiferencia, características reconocidas por los propios jóvenes, no es la más deseable y podría a largo plazo complicar su capacidad de adaptación al sistema

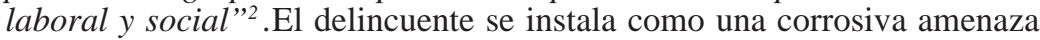
de alteridad, tanto o más peligrosa y disociadora cuanto más la motivación del actuar delictivo es el puro interés antisocial. El delincuente calcula los costos de delinquir, por lo que debe ser disuadido, en última instancia, por el miedo. Por otra parte, se sabe impune porque el gobierno y la justicia no cumplen con su deber de combatir el delito. Tolerancia cero, sin excusas. Un editorial del diario El Mercurio titulado, "Incremento en la autodefensa", expresa con claridad este argumento: "la probabilidad de que un delincuente sea aprehendido y condenado es inferior al 1 por ciento, por lo que la adopción de medidas de defensa por parte de las personas aumenta el riesgo de la actividad delictiva y tienen un potencial papel de disuasión. Un delincuente dudará más en cometer un delito si sabe que puede resultar seriamente lesionado o incluso morir en el intento"3.

Hacia fines de la década, había cristalizado la idea de que la justicia era ineficiente o no funcionaba, o más bien funcionaba como "una puerta giratoria”, de entrada y salida para los delincuentes. La metáfora, un socorrido eslogan electoral de la derecha, expresaba la fuerza que había adquirido la demanda por seguridad y tolerancia cero frente al delito. Las cartas estaban sobre la mesa. En los debates por la segunda vuelta electoral, el futuro presidente, Ricardo Lagos Escobar (2000 - 2006), desafió a su adversario Joaquín Lavín, proclamando: "Yo firmo todo lo que dice Paz Ciudadana” (Guzmán y Ramos 2000: 53). En esta elección, la más reñida desde 1990, en que la derecha estuvo cerca de interrumpir la continuidad de los gobiernos de la Concertación, Lavín había logrado representar con éxito la 
figura de un candidato hacedor que, en sus tiempos como alcalde de la Comuna de Las Condes, la más rica del país, se había posicionado como el campeón de la lucha contra la delincuencia.

Paz Ciudadana inició en 1998, una campaña comunicacional preventiva cuyo público objetivo eran niños y niñas de 6 a 12 años, protagonizada por el perro Don Graf, que se convirtió en su cara visible. La Fundación había obtenido la licencia de una campaña que impulsaba en esos momentos la Asociación Nacional de Prevención del Crimen de los Estados Unidos (NCPC), protagonizada por su mascota oficial, Mr. Gruff, cuyo lema central era "Dale un Mordisco a la Delincuencia” (Take a Bite out of Crime), la que implementó en Chile con escasas variaciones. La campaña consiste en una serie de spots emitidos por la televisión. En ellos, Don Graf da consejos a los niños para cuidarse de delincuentes y drogadictos. La campaña confería a la Fundación un rostro amable y cercano a la ciudadanía, facilitado por el uso de la televisión, medio de emoción y contacto ${ }^{4}$. En sus palabras, apuntaba a entregar información a los niños para que evitasen conductas de riesgo en los espacios considerados más desprotegidos (el hogar, la escuela y el camino de la escuela al hogar), pero los mensajes buscaban también provocar temor, con el fin de que esta emoción quedase asociada en adelante a la conducta de riesgo. Es decir, buscaba una victimización vicaria de los pequeños telespectadores. En un spot de 1998, Don Graf advierte a los niños: estar solo en casa puede ser muy divertido, pero no te descuides... Nunca entregues información a extraños. Prende una radio, cierra puertas y ventanas, enciende luces y así tu casa se verá como una fortaleza. Ya sabes cómo mantener lejos a los delincuentes, porque tú también puedes darle un mordisco a la delincuencia. En otro spot, de 1999, el noble can enseña cómo cuidarse en el autobús, durante el trayecto del colegio a la casa: Siempre guarda tus cosas de valor, lejos de los bandidos. Ubícate siempre en los primeros asientos. En la parte de atrás, nadie podrá ver si te pasa algo. No te expongas y así estarás ayudando a darle un mordisco a la delincuencia.

Los spots, cual "manual de cortapalos", invitan a hacer de la desconfianza hacia el otro una regla de supervivencia cotidiana. Los consejos, sensatos, infunden miedo cuando se acompañan de personajes siniestros o escenarios lúgubres y amenazantes. Don Graf se puede ver como el perro guardián de la desconfianza y del prejuicio hacia los jóvenes populares, que aparecen caracterizados con atuendos hip hop o punk, realizando actos vandálicos o como sospechosos de haber cometido algún delito.

Pero el miedo no era una consecuencia de las campañas ni de la machacona insistencia de los medios en la peligrosidad de la delincuencia, sino que se apoyaba en razones más profundas. A fines de la primera década del retorno a la democracia, el crecimiento económico había tenido costos y muchos no se sentían beneficiados. En 1998, investigadores del Programa de Naciones Unidas para el Desarrollo (PNUD), elaboraron un informe de desarrollo humano en el que señalaban que la mitad de los encuestados, a la hora de evaluar su condición personal, se situaba en el 
bando de los “perdedores”. Dos personajes televisivos de origen popular, "Faúndez” y "El Malo”, mostraron con claridad la polarización impulsada por el modelo neoliberal, entre las aspiraciones y sueños de los chilenos y sus peores miedos y pesadillas. “Faúndez” encarnaba al trabajador convertido en microempresario, que "sale adelante” y es capaz de codearse con ejecutivos de un pujante nuevo sector privado chileno, mientras que "el malo” era la negación de ese camino: un delincuente intrínsecamente malo, sin historia ni motivos. En un comercial, Faúndez va en un ascensor rodeado de ejecutivos y suena un teléfono celular. Todos buscan entre sus ropas, pero es Faúndez el requerido: "Faundez, ingeniería electrónica e instalaciones varias, buenas tardes". Su acento delata su origen popular y las miradas inquisidoras, que luego se transforman en sonrisas, revelan el peso del prejuicio tanto como la aprobación de sus "pares”. Por otro lado, El Malo era simpático y sus “maldades” eran crudas aunque menores, hasta que se sentía interpelado. Entonces, miraba de manera amenazante.

\section{Tolerancia cero made in Chile}

La orientación de las políticas de Paz Ciudadana, reflejaba la ambivalencia de las medidas de tolerancia cero y, en tal sentido, la Fundación se abrió a las críticas que formularon algunos expertos. Las campañas del tipo "Dale un mordisco a la delincuencia” promovían a un ciudadano responsable que reduce las oportunidades de los delincuentes para delinquir, pero al mismo tiempo, generaban el efecto no deseado de encerrar a los ciudadanos honestos en sus casas y "regalarle la calle a los delincuentes". Enterados de que "la ONU y la revista Forbes habían designado a Toronto como la ciudad más segura y con mejor calidad de vida en el mundo”, en 1999 el economista Carlos Valdivieso, gerente de la Fundación y otros profesionales, viajaron a conocer la experiencia y firmaron un convenio con el Departamento de Desarrollo Urbano de Toronto para reproducirla en Chile en las comunas populares de La Granja y Peñalolén, controladas por alcaldes de la coalición derechista Alianza por Chile. La experiencia era defendida como"lo último en anti delincuencia: una seguridad sin rejas" y apuntaba a la implementación de una serie de medidas para la prevención situacional del delito en el entorno urbano y para aumentar la sensación de seguridad de los habitantes de los barrios. Defendida como réplica menos represiva de la tolerancia cero, en la que se inspiraba, encarnaba el espíritu de los nuevos programas comunales que comenzaban a extenderse por el país. Sentirse seguro no significa aislarse, encerrarse. Por el contrario, sentirse seguro es adueñarse del espacio público, hacerlo suyo. Creo que el mejor vigilante es la persona a la que le gusta su barrio, explicaba en su oportunidad Carlos Valdivieso ${ }^{5}$.

En diciembre de 2000, el principal think tank de la derecha chilena, el Instituto Libertad y Desarrollo organizó un seminario que contó con la participación de Carlos Medina, director del área de educación del Manhattan Institute, Michael O’Connor, experto en planificación de seguridad urbana y William Bratton, ex jefe de la Policía de Nueva York. En el 
evento, se expuso la estrategia de tolerancia cero ante una audiencia de alcaldes de derecha de la región Metropolitana y otras comunas del país. La idea del encuentro era implementar una suerte de asociación entre municipalidades para enfrentar de manera común los problemas de seguridad. En la oportunidad intervinieron, además, Cristián Larroulet, director ejecutivo del Instituto Libertad y Desarrollo; Eugenio Guzmán, director del programa político de ese organismo y Joaquín Lavín, a la sazón alcalde de Santiago, quien cerró el seminario. Bratton, el principal orador, destacó en especial el tema de los grafitis y los definió como "un cáncer de la ciudad que con su permanencia da a entender a los delincuentes que hay zonas descuidadas

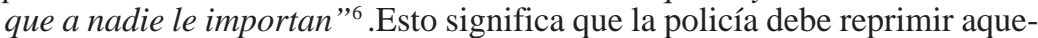
llos comportamientos que, aun no constituyendo propiamente un delito, resultan molestos, fastidiosos y ofrecen al ciudadano una imagen degradada de la ciudad: los graffiti, el pedido agresivo de limosna, la insistencia de quienes lavan los cristales de los vehículos en los semáforos, la prostitución callejera, la embriaguez en lugares públicos, la presencia de sin techo en las calles y demás situaciones similares. Los conceptos conocidos del Plan de Tolerancia Cero, se presentaban ante todo como una "fuerte señal" en materia de delincuencia y de seguridad ciudadana. Desde Nueva York, se exportaba la doctrina de la tolerancia cero, instrumento de legitimación de la gestión policial y judicial de la pobreza que molesta -la que se ve, la que provoca incidentes y desagrados en el espacio público y alimenta por lo tanto un sentimiento difuso de inseguridad e incluso, simplemente de malestar tenaz e incongruencia” (Wacquant 2000: 32)

Paz Ciudadana había pasado a ser un actor consolidado en la definición de las políticas públicas de seguridad de los gobiernos de la Concertación. El año 2001, durante el gobierno de Lagos, el Ministerio del Interior, asociado con la Fundación, puso en marcha el plan "Comuna Segura, Compromiso 100”. Su objetivo era coordinar la participación de la comunidad en la definición de los problemas de seguridad y financiar proyectos de prevención de la delincuencia.

Bratton volvió a Chile en 2001, invitado esta vez por el alcalde de la Municipalidad de La Florida, Pablo Zalaquett. El Mercurio destacó el perfil del ilustre visitante: "Gracias a su gestión, el súper policía-como lo bautizó la prensa norteamericana- hoy es considerado el máximo estratega contemporáneo de los sistemas de seguridad ciudadana en el mundo"7.Esta vez se destacaba, dentro de las estrategias del plan de tolerancia cero, el sistema de gestión del trabajo policial, en que los policías a cargo de determinados sectores son responsabilizados por la cantidad de delitos que en ellos ocurren, lo cual se hace posible mediante un sistema de información y evaluación, el “CompStat”. Habría que esperar hasta el año 2011, durante el gobierno de Sebastián Piñera (2010 - 2014), para que Carabineros adoptara oficialmente este sistema de gestión, que fue bautizado simplemente como "Stad” (Sistema Táctico de Análisis Delictual).

En 2004, un proyecto de ley difundido como "la tercera es la vencida”, versión criolla de la ley conocida como “3 strikes”, aplicada en California 
desde 1994, fue rechazado por el Congreso. El proyecto proponía aplicar en forma obligatoria una pena superior a 15 años de cárcel, cuando se tratara la tercera condena. Carlos Medina, del Manhattan Institute, residente en Chile, aseguraba que la delincuencia disminuía con este tipo de legislación. Replicando a los detractores, aclaraba que en USA la aplicación de la ley había resultado injusta en algunos casos porque no quedó en claro que sólo se aplicaría a los delitos graves y se hizo una enmienda a la ley para que jueces o fiscales puedan eliminar uno de los cargos cuando no son delitos graves. En Chile su impulsor, Joaquín Lavín, en la época alcalde de Santiago, dijo que "la norma propuesta se asemeja en que la condena por tercera vez de un delito grave no debe ser menor a 15 años de cárcel, pero además para otros ilícitos, como el "lanzazo" o los asaltos, cuando el delincuente es detenido por tercera vez, no pueda salir en libertad bajo fianza" .

En la década de los 2000, se instala un diagnóstico de los jóvenes como generación desarraigada y desconectada del mundo adulto. Jóvenes "hijos de nadie", que debían extremar los recursos para constituirse como tales. Se anunciaba que la sociedad chilena se estaba transformando progresivamente en una "sociedad del riesgo", en la cual las personas viven en condiciones esencialmente móviles, teniendo que adaptarse a condiciones cambiantes. Esta esencial movilidad (laboral, espacial, de estado civil, educacional, etc.), si bien resulta una oportunidad para muchas personas, constituye una amenaza para otras, sobre todo aquellas con menor nivel educativo, con menos recursos, que tienden a percibir más negativamente los cambios y a procesarlos como “inseguridad” (INJUV 2006).

Este discurso sobre la generación joven como población en riesgo, se volvería inaudible con la irrupción de las protestas estudiantiles el año 2006 y, definitivamente, el 2011. Tras el ciclo de movilizaciones sociales que comienza a manifestarse desde 2006, y que se afirmó con las movilizaciones estudiantiles del año 2011, la sociedad chilena expresó abiertamente su desencanto. La conciencia creciente de la injusticia de un modelo que favorece la desigualdad, la especulación financiera, la corrupción y el robo a gran escala, unida a la frustración ciudadana con una clase política ajena a sus demandas, produjo un nivel de movilización que se creía ya perdido. Sin embargo, como veremos luego, iniciada la década del 2010, otros discursos y programas darían una nueva vuelta de tuerca al desarrollo del campo del control punitivo del delito de los menores de edad.

El año 2006, las protestas estudiantiles habían roto el silencio de la transición. Ese año, bautizado como el de la "revolución de los pingüinos", se instaló la demanda por la gratuidad del pase escolar y luego las críticas se extendieron a la municipalización de la educación, instaurada por la Ley Orgánica Constitucional de Enseñanza (LOCE), durante la dictadura de Pinochet. Entre gritos de: "Y va a caer, y va a caer, la educación de Pinochet”, los estudiantes expresaban la primera crítica ciudadana a uno de los pilares del modelo neoliberal. La respuesta de la elite, que logró aprobar apresuradamente una Ley General de Educación (LGE), no fue ca- 
paz de ofrecer una alternativa a la gestión municipal de los liceos, sino que prefirió reafirmar la “viabilidad” de la "política de los acuerdos”, dejando las cosas tal como estaban. Pero, el horno ya no estaba para bollos. La falta de acogida a la demanda estudiantil, generó una gran frustración en la ciudadanía, instaló la semilla de la desconfianza institucional y afirmó la idea de que había que reclamar con más fuerza, desde otras tribunas (Mayol2012).

Las movilizaciones y manifestaciones alcanzaron un alto nivel el año 2011. Ese año se inauguró con las protestas en contra del proyecto hidroeléctrico "Hydroaysén”, continuó con la movilización de los habitantes de la región de Magallanes en contra de las alzas en los precios del gas, siguió con protestas de la población de Calama en contra de la instalación de una termoeléctrica y culminó con una masiva y prolongada movilización estudiantil, secundada por padres y profesores, en pos de una "educación pública gratuita y de calidad" y por el "fin al lucro", grito que se extendió como reguero de pólvora a todos los ámbitos de los derechos sociales que han sido entregados a la voracidad de los negocios. Las calles de la capital y regiones estuvieron ocupadas por jóvenes, trabajadores y simpatizantes del movimiento estudiantil a lo largo de siete meses, acompañado de la paralización de establecimientos educacionales, en virtud de masivas y recurrentes “tomas”. El gobierno reaccionó de la manera acostumbrada: en nombre de la seguridad y el orden público, intentó prohibir las tomas de colegios y las manifestaciones de los “encapuchados” (estudiantes que ocultaban su identidad), anunciando el envío de un proyecto de ley, curiosamente conocido como "ley Hinzpeter" (nombre del Ministro de Interior de la época), por el cual se criminalizaban las tomas y el accionar del movimiento estudiantil.

Los colegios tomaban represalias y expulsaban a los dirigentes y voceros de las tomas. Numerosos recursos ante las Cortes de Apelaciones fueron acogidos y los estudiantes debieron ser reintegrados. Entre los argumentos esgrimidos por los fallos estaban el que los estudiantes no habían sido oídos, que no se les había permitido presentar pruebas en su favor y que las instancias que habían resuelto las expulsiones no eran imparciales, los mismos argumentos que poco años antes habían sido rechazados, como ocurrió con el asunto del "jarrazo”, que discutiremos en la siguiente sección. Como señalaba el Informe de Desarrollo Humano del PNUD del año 2012: "Mientras la sociedad ha perdido los miedos, la elite dirigente parece acuñar miedos relevantes”(PNUD 2012: 42).

En la segunda década del nuevo siglo, la contraposición entre integrados y precarizados abarca todo el cuerpo social, tal como se manifiesta en la existencia de tres grupos que simbolizan la discriminación hecha deseo colectivo en el Chile de hoy: "cuicos", "aspiracionales" y "flaites"9 . Distintas categorías sociales que se mueven en un espacio social estriado: los "cuicos" o los de condición social acomodada, los "aspiracionales", que por la vía del consumo y la ostentación quieren aparentar una promoción social exitosa y, finalmente, los “flaites”, herederos del sujeto pobre marginal de otras décadas, en una modulación desafiante y amenazadora. 
Los primeros no se avergüenzan de decir su nombre, son los ganadores en el sistema neoliberal chileno. Los segundos son el depositario de los miedos de la mayor parte de los ciudadanos, son el público de las campañas de seguridad ciudadana y de tolerancia cero. Los últimos, los delincuentes, son los sujetos peligrosos que no pueden ser nombrados, que no pueden ser oídos ni pueden ser vistos.

\title{
Una mirada a los discursos y tecnologías de control desde la entrada en vigencia de la ley de responsabilidad penal adolescente
}

\begin{abstract}
Después de la entrada en vigencia de la ley de responsabilidad penal de adolescentes en el año 2007 (que regula la responsabilidad penal de los adolescentes mayores de catorce y menores de 18 años) y particularmente durante la actual década, los presuntos delitos y transgresiones de los niños menores de catorce años poblaron la vitrina de los medios. Los casos de "niños delincuentes”, como "Cisarro”, “Miguelito”, "Byron” y otros, fueron destacados por los medios de comunicación con tonalidades de alarma, en el ya extendido contexto de la instalación de la agenda de la seguridad ciudadana y de las políticas de tolerancia cero en nuestro país. Se trata de una explosión mediática que no se corresponde con la realidad de un fenómeno menor cuya magnitud no aumenta sino que, por el contrario, va en disminución ${ }^{10}$. Revisamos a continuación, un poco al pasar, algunos de estos casos, que ilustran el despliegue de un abanico de respuestas de control frente a los delitos y transgresiones de los menores de edad.
\end{abstract}

El día 14 de julio de 2008, la estudiante María Música Sepúlveda arrojó un jarro de agua a la Ministra de Educación, con motivo del cierre de los “Diálogos Participativos por la Educación Pública”, organizados por el Ministerio, en el que participaban estudiantes y profesores. El tema del diálogo era la futura ley general de educación (LGE), propuesta por el gobierno en reemplazo de la cuestionada ley de educación de la dictadura (LOCE). Los estudiantes estaban exasperados por la represión de Carabineros y la estudiante fue, al parecer la que llegó más lejos en su protesta por hacerse oír ${ }^{11}$.Pronto la reacción ante el caso reveló que todos los actores adultos estaban dispuestos a aplicar una sanción frente al acto transgresor de María Música, siguiendo una lógica tutelar. La Ministra de Educación, que había comprendido inicialmente la motivación que llevó a la niña a volcarle el jarro con agua, cuando asimiló el acto a una vuelta de mano de los estudiantes por el accionar del carro lanza aguas ("guanaco") de Carabineros, posteriormente criticó la conducta de la niña y la atribuyó a una mala formación recibida de la madre, quien no solo no la había reprendido por su comportamiento sino que la justificaba. Insinuó que debía ponérsele un tutor, que cautelara su educación. El día 2 de agosto, el emblemático liceo público Darío Salas, la expulsó.La “clase política” y la iglesia católica se plegaron a las reprobaciones. La prensa informó que en un colegio católico de la ciudad de Puerto Montt, rogaron para que ningún otro niño se 
atreviera a imitar a María Música y para "sacarle el diablo de adentro"12. Los medios de comunicación recogieron con entusiasmo los cuestionamientos y repitieron, una y otra vez, la imagen del lanzamiento del jarro con agua. El día 4 de septiembre, la Corte de Apelaciones de Santiago declaró inadmisible un recurso de protección ante la medida de expulsión, presentado por la madre de María Música Sepúlveda. El recurso señalaba que "los hechos que condujeron a la expulsión de María Música del Liceo se originan fuera del Liceo, en una actividad pública al margen de sus actividades, que no se encuentra regulada por las normas que regulan la convivencia escolar"13.

Finalizaba julio de 2009 y los televidentes y lectores se enteraban, con asombro, de la detención de Cristóbal C. M., un niño de 9 años, conduciendo un vehículo robado, en compañía de otros tres menores de entre catorce y dieciséis años. Se informó que el niño conducía el coche y que habría chocado al intentar huir. Lo acompañaban el "loquín”, "el gorila” y "el garra”, todos apodos que denotaban su procedencia social y su cercanía al mundo delictivo. En un lapso de tres días, los medios cubrieron la internación y posterior fuga de Cristóbal e hicieron notar su modo de hablar y comportarse, inusual para un niño de su edad: "Tribunal de familia ordena internación del "Cisarro" en Centro del SENAME. A la salida del juzgado, el menor de 10 años reaccionó de forma violenta y dijo "déjenme tranquilo", lanzando patadas ${ }^{14}$. Del centro fue "rescatado" al día siguiente por otros menores. El domingo 2 de agosto, el diario El Mercurio titulaba "Carabineros recaptura al "Cisarro", tras fuga armada desde centro del SENAME". El epígrafe de la noticia señalaba: "Solo estuvo 26 horas en el recinto hasta que un grupo trepó una pandereta e intimidó a uno de los guardias". Testigos independientes señalaron que no hubo tal intimidación ni tal arma y que los menores salieron por la puerta del recinto. Cristóbal fue descrito como un niño "que se creía" gánster, de un carácter incorregible y violento y capaz de un actuar delictivo, como es patente en los términos que emplea la nota. De hecho, agrega: "tras quedar en libertad, el delincuente juvenil y los rescatistas abordaron un taxi que los esperaba". Formalmente, el niño no estaba acusado de cometer un delito, por tanto, lo particular del caso no era que hubiese intentado huir, lo que podía hacer sin dificultad, sino que fuese ayudado por otros niños. La huida fue breve, generando su "detención” número 17, según la contabilidad policial. Su rostro estuvo en la portada de un matutino. La portada insinuaba que Cristóbal no estaba en sus cabales y que, por su comportamiento, él y sus amigos no podían ser considerados niños. Luego de esta detención, Cristóbal fue ingresado a la Unidad Psiquiátrica del hospital Luis Calvo Mackenna. El tribunal descartó su posterior traslado a un recinto especializado de SENAME en Valparaíso y optó por dejarlo en la unidad siquiátrica, tras recibir un informe que señalaba su adicción al alcohol y a las drogas. Las "locas" circunstancias de su frustrada huida, reforzaron también la idea de que el niño tenía "problemas mentales". En el recinto estuvo siete meses. Luego de una posterior huida de un centro de tratamiento de drogas en $\mathrm{La}$ Florida, donde nuevamente habría sido "ayudado" por dos adolescentes, manifestó su deseo de volver al Hospital Calvo Mackenna, donde decía 
haber recibido un mejor trato. Significativamente, luego de esta última detención en la que fue formalizado por amenazas, ya con catorce años, el noticiero de la Televisión Nacional, TVN 24 horas, lo catalogó como “el niño símbolo” de la delincuencia juvenil. La exposición descarnada del caso de Cristóbal llevó a un Tribunal de Familia a prohibir que los detalles de su vida personal o médica fueran ventilados en la prensa. En la actualidad, sabemos que está cumpliendo con una sanción de libertad asistida, a la que fue condenado por intentar asaltar una bencinera... con una pistola de juguete.

El caso más reciente de “niños delincuentes”, el de Byron A.H.M., en varios aspectos recibe un tratamiento similar al de Cristóbal, pero, con una importante diferencia: Luego de su primera detención, su familia comenzó a ser tratada por psicólogos del programa de Terapia Multisistémica, mientras que Byron era internado en el mismo establecimiento de SENAME en el que se encontraba recluido en aquel entonces, Cristóbal, para su “contención”. El Subsecretario de Prevención del Delito dijo en esa oportunidad: "Su familia está siendo tratada con una terapia multisistémica traída desde Estados Unidos (...) Para lograr que el niño se pueda reinsertar, además de intervenirlo a él, hay que hacerlo con su familia. Así lo estamos haciendo, con su madre, hermana y primo".Tras su siguiente detención, el tribunal de familia ordenó como medida de protección internar a Byron en un centro siquiátrico. Los siquiatras aprovecharon de descalificar la terapia multisistémica, al señalar que "la intervención de psicólogos no es apropiada, pues estos son casos clínicos que requieren intervención médica”.

Cierra esta presentación el caso “Peaje Quino”, de aplicación de la legislación antiterrorista a menores de dieciocho años, en abierta violación de sus derechos y en una exhibición de los criterios punitivos más extremos. En este caso, el gobierno hizo evidente que la razón de la aplicación de la ley antiterrorista no eran los delitos cometidos, sino sus presuntos autores mapuche. La Corte Suprema no avaló la aplicación de la ley antiterrorista y obligó al Ministerio Público a recalificar los delitos. Los imputados recuperaron primero su libertad y luego, en agosto de 2012, fueron sobreseí$\operatorname{dos}^{15}$. Pero lo peor estaba por venir. La absolución sólo tuvo efecto para los mayores de edad. La persecución continuó en contra de los dos menores de edad detenidos. Las implicancias racistas no pasaron desapercibidas, menos tratándose de jóvenes de los pueblos originarios.

Se instalan también, de una manera silenciosa aunque visible en los medios, nuevos hitos del discurso criminológico de la tolerancia cero, en la forma de acciones y programas de prevención del delito para niños en riesgo e inimputables, tales como “Vida Nueva” y “Terapia Multisistémica”, que emergen con fuerza en un espacio que los operadores se resisten a estriar penalmente, confiando en poder captar más casos en el sistema de protección por la vía de estos nuevos programas de prevención de los riesgos. Con estos planes se ha querido implementar una “economía” de control más eficiente de los delitos que cometen los menores de catorce 
años, ya que los expertos coinciden en que la solución no pasa por rebajar nuevamente la edad de responsabilidad penal: "se estima que bajo esa edad estamos frente a sujetos que están en desarrollo"16.

El programa“Vida Nueva” es un plan para instalar un modelo de gestión local de casos de niños y adolescentes vulnerados en sus derechos, inimputables e infractores de la ley penal, a partir de la información generada por el Programa de Seguridad Integrada, PSI 24 Horas de Carabineros. En el programa se coordinan la Subsecretaría de Carabineros, el SENAME, la Subsecretaría de Prevención del Delito del Ministerio del Interior y Seguridad Pública y el Ministerio de Salud, que se integró el año 2011.El presupuesto del programa creció en un 71\% entre 2010 y 2012, llegando a 5.000 millones de pesos (4.992.810.000). El incremento se debió a la inclusión dentro de sus componentes, del nuevo programa de "Terapia Multisistémica”. Este programa innova en la definición de una red de tratamiento de niños "vulnerables” e "inimputables”, que se gestiona como población en "riesgo”, es decir, alejándose del enfrentamiento de la peligrosidad de forma directa y “cara a cara”, doblando la pretensión estadística (estática) en dirección de una gestión de trayectorias (dinámicas). Novedosa tecnología de poder, que ejerce un control a distancia (detección del riesgo y asignación de un tratamiento compensatorio) y, a la vez, localizado gestión individual de los casos, con una pretensión de integralidad-.

En cuanto a la terapia multisistémica, el diarioEl Mercurio dedicó un editorial para referirse al programa como un "antes y un después” en materia de políticas preventivas en el país. El editorial, posiblemente escrito por Paz Ciudadana, da a entender que el gobierno va por el camino correcto en su afán de ganar "la guerra contra la delincuencia”. El nuevo gobierno de Bachelet (2014 - 2018), ha continuado con la implementación del programa, que ha rebautizado como de Apoyo Integral Familiar, anunciando su ampliación a 11 nuevas comunas durante el actual periodo de Gobierno, llegando a un total de 36 comunas del país el año 2016, pensando invertir más de 24 mil millones de pesos hasta el año 2018(24 Horas 2007). La terapia multisistémica, que en su contexto original se utiliza para enfrentar los comportamientos antisociales de los delincuentes juveniles violentos y crónicos, no de los niños inimputables, encarna a la perfección la "tendencia de punta” en los actuales modelos de control: actuación preventiva a través de la gestión de los riesgos, tratamiento de intensidad intermedia sobre el entorno ecológico del sujeto intervenido, actuación asistencial orientada a radicar la responsabilidad del control en el grupo familiar, colonización y subordinación tecnológica, y rendición de cuentas a una agencia extranjera.

Las tendencias observadas en la instalación y desarrollo de los temas de seguridad ciudadana y violencia delictiva juvenil en la opinión pública y en las acciones y políticas gubernamentales, destacan la conformación de un espacio discursivo que convoca diferentes estrategias de control del comportamiento de los menores que cometen delitos, pero también transgresiones a ciertas normas sociales. Los discursos que se dicen en los 
casos que hemos presentado, en algunas noticias destacadas, en los espacios de la televisión, en las medidas de tolerancia cero, en los programas de prevención de la delincuencia, describen diferentes definiciones ideológicas sobre el control de los menores delincuentes, que se decantan en torno a diferencias de edad establecidas institucionalmente, como en el caso del sistema de responsabilidad penal adolescente. Este sistema, que regula los delitos que cometen los menores que tienen entre catorce y diecisiete años, se consolida como una frontera bajo la cual se organiza la punición de los menores de catorce años y por sobre la cual, o en su reemplazo, se organiza el tratamiento punitivo de los menores pertenecientes al pueblo mapuche.

Diferentes discursos y tecnologías se manifiestan en los diferentes casos: tutela, correccionalismo, responsabilidad penal adolescente, segregación punitiva. Estrategia tutelar, en el caso de “la niña del jarrazo”, ejemplo de reproche moral. Estrategia correccional, en los casos de "Byron” y "Cisarro", donde se oscila entre el encierro "proteccional” y el encierro "sanitario”, sin más puntos en común que la privación de libertad para la normalización del comportamiento y el control conductual. Estrategia de segregación en el tratamiento del caso “Peaje Quino”, distante y despersonalizado. Aquí, el colorido de los personajes infantiles desaparece, en favor de una inscripción del caso en un contexto de guerra. La presencia de personajes sin rostro, la irreductible identidad comunitaria de los detenidos, el carácter fantasmagórico de su lucha, legitima un tratamiento segregador y excluyente de la conflictividad de los adolescentes involucrados.

El sistema parece tender a conformar una entidad continua de vigilancia y control; se decanta del lado de la intensificación de la respuesta punitiva, en la idea de "adelantar" el castigo, de disponer de formas de control y vigilancia a una edad cada vez más temprana. "Castigar cuanto antes, antes de que sea tarde”, pareciera ser la consigna implícita en la tendencia general. La necesidad no solo de castigar sino de extinguir toda posibilidad de que la conducta se repita, esta vez desde la ilusión de un perfecto control técnico y a distancia, que permita anticiparse en tiempo y lugar a su posible incidencia. Esta pretensión -tal como lo fue antes a su manera el correccionalismo- refleja el miedo de los sectores dominantes y de otros sectores significativos de la población, al desborde social, al "reparto" y al "despojo”, temidas consecuencias de las enormes desigualdades sociales que todos perciben. Tolerancia cero made in Chile: Una respuesta punitiva intolerante ante el miedo y la inseguridad, siempre mayores que el riesgo real.

De distintas maneras, el lenguaje de las noticias expresa asociaciones positivas y negativas con respecto a los protagonistas involucrados. Se magnifica el daño que causan los menores con sus delitos y se minimizan o ignoran las vulneraciones sufridas por estos o los abusos que cometen en su contra los adultos y agentes del orden. Su historia es interpretada de manera simplista y siempre en función de su actual realidad “criminal”. En general son vistos como extraños al cuerpo social, como una “invasión” de 
elementos exógenos, que tienden a perturbar el orden social y nunca como un producto de la misma sociedad que los rechaza. Sus motivaciones son presentadas como irracionales. Hay elementos comunes a todos los casos y es que sistemáticamente falta el punto de vista de los menores afectados, nadie les pide su opinión, siempre hablan acerca de o por ellos los adultos y particularmente, los “especialistas”.

En su propuesta de análisis del discurso noticioso y en sus investigaciones sobre el racismo, Van Dijk, señala que en la estrategia básica del discurso ideológico, se trata de: "Poner énfasis en Nuestros aspectos positivos; Poner énfasis en Sus aspectos negativos. Quitar énfasis de Nuestros aspectos negativos. Quitar énfasis de Sus aspectos positivos” (Van Dijk 2003: 58). Este "cuadrado ideológico" es reconocible en las construcciones discursivas en torno a los casos: del delincuente como enemigo interno; de los niños incontrolables con "anomalías" conductuales o diagnosticados como personalidades antisociales, sin redes de protección familiar; de los que son ajenos a la convivencia educada e incurren en actos violentos; de los que carecen o no han gozado de un adecuado cuidado y supervisión paterno; así como en los supuestos sobre los que están construidos los programas.

Los medios de comunicación constituyen una institucionalidad relevante en el proceso que incide en el carácter centralmente punitivo del sistema de justicia en general y de la justicia adolescente en particular, ejerciendo presión para una mayor eficiencia persecutoria y dificultando las decisiones orientadas a partir de los principios minimalistas, que en teoría debiesen orientar el funcionamiento del sistema. Por ejemplo, se acusa que la presión de los medios es tan intensa, que incluso llega a constituir una justicia paralela -una "justicia mediática"-. Una jueza de garantía narraba que es más probable que sus decisiones sean revocadas por la Corte de Apelaciones, cuando se alejan de las exigencias de los medios de comunicación. Si las causas son mediáticas, entonces los actores igualmente tienden a mediatizarse: "Nosotros como jueces de garantía, estamos muy complicados con la opinión pública, con adultos y menores (...) No le voy a decir quien, pero aquí las tallas (bromas), cuando una causa va a tener prensa, son: "ponte bonita, vístete bien, anda a la peluquería". Yo me debo a mi público. El problema es que yo siento que, a veces, es la opinión pública la que está dirigiendo, los periodistas”"17.

Los entrevistados admiten que los medios no solo afectan la actuación de la justicia, sino que construyen sistemáticamente la figura del menor delincuente como un ser temible y amenazante. A mediados de los años dos mil, cuando la mirada punitiva estaba totalmente centrada en la delincuencia de menores, el arranque de la ley 20.084 marco un breve punto de inflexión, a raíz de del incendio ocurrido en 2007 en el Centro de Puerto Montt de SENAME, en la que murieron ocho adolescentes. Por breve tiempo, los medios desplegaron una mirada más comprensiva del fenómeno ${ }^{18}$. 


\section{Conclusiones}

El tratamiento discursivo de la delincuencia de menores por los medios, tiene la estructura de un proceso judicial: se trata de definir qué pasó, quien hizo que, quienes son los responsables y que pena o medida debe aplicarse. Los casos de niños inimputables son presentados como narraciones que dan cuenta de trayectorias delictivas que se vienen construyendo desde muy temprano en las vidas de los protagonistas de la noticia. La selectividad del sistema de control, que criminaliza preferentemente a los niños más vulnerados, a los fragilizados, a los que "han incurrido en falta", hace aparecer este hecho como natural. La imagen de los niños populares, inseparable de su peligrosidad, es también la expectativa de un público que quizá no espere otro protagonista de la noticia que el que efectivamente tiene ante sus ojos.

Concluimos estas líneas afirmando el carácter mediador de los conceptos de discurso ideológico y de tecnologías de poder, cuando se aplican a analizar el proceso de instalación de las ideas de la tolerancia cero, del discurso de la seguridad ciudadana y el despliegue de las nuevas modalidades de intervención programática para el control de los menores inimputables. Estos conceptos mediadores nos dan pistas adicionales para explicar cómo las transformaciones del capitalismo neoliberal influyen en las mutaciones de los regímenes de control, en las específicas condiciones de la formación social chilena. LoÏc Wacquant ha vinculado las políticas de "liberalización” del mercado del trabajo y el desmantelamiento del Estado social con el fortalecimiento del Estado penal. En USA en veinte años la población reclusa se ha multiplicado por cuatro hasta alcanzar la cifra de dos millones de reclusos. Las “cárceles de la miseria” están íntimamente vinculadas con las políticas de orden que se ligan con las mutaciones del sistema productivo y las consecuencias excedentarias del mercado capitalista del trabajo (Wacquant 2000). Pero estas relaciones, que tienen un efecto político, pueden esclarecerse mucho más si se analiza la lógica específica y relativamente autónoma de las nuevas y viejas tecnologías de control y de los discursos ideológicos que las sustentan y justifican. Las cárceles de la miseria y las políticas de tolerancia cero tienen un efecto ideológico legitimador del orden capitalista neoliberal. En la actualidad hay un manejo consciente de las posibilidades que esa ideología ofrece para la manipulación de los sentimientos del público y la desarticulación de las demandas sociales. ¿Para qué molestarse con reformas si se tiene a la mano la posibilidad de llamar a la unión solidaria frente al peligro antisocial? El miedo a perder lo que se cree propio y el lugar de cada cual en el sistema -aunque sea precario- son poderosos alicientes para demonizar a los menores delincuentes y distraer las energías de las reivindicaciones ciudadanas de la denuncia de las fechorías cometidas por los delincuentes de cuello blanco.

El análisis de los discursos de los medios de comunicación reafirma la ligazón que existe entre el modelo neoliberal y las políticas de seguridad ciudadana y de tolerancia cero. Parece tratarse de un matrimonio indisoluble que no se había visto amagado sino hasta el cercano año 2011, en el que 
la demanda de los estudiantes por el "fin al lucro", remeció discursiva y prácticamente los pilares del sistema.La lógica neoliberal se encarna en los deseos, en la construcción cultural de sentido común de una igualdad en que todos pueden ser propietarios, pero en la que algunos deben ser sacrificados para que otros puedan prosperar. En definitiva, la lógica de la competencia, que unida a la de la desregulación, ha llevado a una transformación radical del concepto de delito y de delincuente. La lógica de la tolerancia cero dualiza lo social, como el mismo modelo neoliberal de sociedad que emula, relajando ciertos controles al tiempo que endurece otros. La tolerancia cero a la chilena no solo criminaliza la pobreza, sino que pobretiza la delincuencia, de acuerdo con la acertada expresión de Salinas (Salinas 2012). La modernización neoliberal solo ha despenalizado los ilegalismos de las clases pudientes y haciendo honor a su ideología desreguladora, prefiere entregar la resolución de estos asuntos a la libre concurrencia. En cambio, los controles se endurecen y amplían cuando de los sectores populares se trata. Un dispositivo moral, en definitiva, una fórmula para deslegitimar las demandas de los sectores populares y oscurecer el sentido de sus luchas. Pero, hay otro escenario que se dibuja también y este se relaciona con la demanda por los derechos sociales. Hay una memoria histórica alternativa que nos recuerda la igualdad de otro modo: de que somos todos iguales porque tenemos los mismos derechos.Hasta ahora el Estado ha renunciado a poner freno a la mercantilización de los derechos sociales, de la que continúa cautivo nuestro ordenamiento democrático pos dictatorial. Precisamente, se trata de la lucha por los derechos sociales en contra de la criminalización y la marginación. 
Polis, Revista Latinoamericana, Volumen 15, $N^{\circ} 44,2016$

\section{Notas}

1 Diario La Segunda, 3 de octubre de 1990.

${ }^{2}$ Diario La Tercera, 7 de noviembre de 1999.

${ }^{3}$ Diario El Mercurio, editorial 3 de marzo de 2000

4 "Los medios sirven sobre todo a la publicidad y al entretenimiento (...) la radio es por encima de todo un instrumento musical y la TV un largometraje transmitido en casa" (Romano1993: 109).

5 "Lo último en antidelincuencia: seguridad sin rejas”, El Mercurio, sábado 26 de agosto de 2000 .

6 "Expertos extranjeros: Análisis a fondo de problemas de seguridad”, El Mercurio, Miércoles 6 de diciembre de 2000.

${ }^{7}$ El Mercurio, sección Economía y Negocios, martes 10 de Septiembre de 2002

${ }^{8}$ El Mercurio, “Combate a la delincuencia: "La tercera es la vencida tuvo positivos efectos en California”, 23 de Agosto de 2004

${ }^{9}$ El Mostrador, 16 de febrero de 2015., http://www.elmostrador.cl/opinion/2015/02/ 16/falta-de-respeto-en-chile-cuicos-aspiracionales-y-flaites/

${ }^{10}$ La cantidad de menores de 14 años vigentes en el sistema de protección por "faltas y delitos no penalizables” disminuyó de 1.027 en 2010 a 747 en 2013, lo que representa un descenso de 27.3\% (SENAME2010, 2013).

${ }_{11}$ Diario El ciudadano, 14 de julio de 2008. http://www.elciudadano.cl/2008/07/14/ 2253/secundaria-de-catorce-anos-castigo-a-privatizadora-ministra-de-educacion/

12 Entrevista a María Música, revista Punto Final, 25 de julio de 2008. http:// www.puntofinal.cl/667/musica.php.

${ }^{13}$ http://lamusicalibre.wordpress.com/2008/08/01/autoridades-del-dario-salas-prohibeningreso-de-maria-musica/

14 Diario La Tercera, 31 de julio de 2009. http://diario.latercera.com/2009/07/31/01/ contenido/9_6514_1.html

15 http://diario.latercera.com/2012/08/25/01/contenido/pais/31-116835-9-absuelvena-ocho-mapuches-acusados-en-caso-de-asalto-a-peaje.shtml.

${ }^{16}$ Lo peculiar de este argumento, es que es el mismo que se usó en su momento para justificar la ley de responsabilidad penal adolescente. http://prontus.ivn.cl/cambio21/ site/artic/20120629.

${ }^{17}$ Las entrevistas fueron realizadas por integrantes del grupo de control social de la Universidad Academia de Humanismo Cristiano en el año 2013. 
18 “Hasta ayer, para la opinión pública, todos eran delincuentes, hoy día -con la muerte- son niños. Esta tragedia debe hacer que la sociedad deje atrás esa mentalidad en que sólo el encierro y el aislamiento es la única medida para garantizarnos seguridad”, en: http://www.emol.com/noticias/nacional/2007/10/22/279402/ defensor-regional-ytragedia-en-puerto-montt-el-encierro-no-es-la-solucion.html 
Polis, Revista Latinoamericana, Volumen 15, No 44, 2016

\section{Bibliografía}

24 horas (2007), Programa de Seguridad Integrada para Niños, Niñas y Adolescentes. Dirección de Protección Policial de la Familia, Carabineros de Chile y Subsecretaría de Carabineros, Ministerio de Defensa Nacional, Santiago.

Abril, G. (2005), Teoría General de la Información, Cátedra, 2 Ed., Barcelona.

Álvarez-Uría F. (1998), “Retórica neoliberal. La gran ofensiva de los científicos sociales contra las políticas sociales en USA”, Claves de la Razón Práctica $\mathrm{N}^{\circ}$ 80, Madrid.

Casasús J. (1985), Ideología y Análisis de Medios de Comunicación, Mitre, Barcelona.

Castel R. (1984), La Gestión de los Riesgos, Anagrama, Barcelona.

Foucault M. (1991), “La gubernamentalidad”, en: Espacios de Poder, Endymión, Madrid.

Ídem (1996), Genealogía del Racismo, Altamira, Buenos Aires.

Garland D. (2005), La Cultura del Control, Gedisa, Barcelona.

Guzmán J. y Ramos M. (2000), La Guerra y la Paz Ciudadana, LOM, Santiago.

Hoecker L. (2000), “Antecedentes acerca de la instalación del problema de la inseguridad ciudadana como preocupación prioritaria de la opinión pública”, Revista de la Academia N 5, LOM, Santiago.

Ídem (2010), “Generando nuestros extraños. Legitimación y reproducción del sistema de justicia infanto-juvenil reformado”, Revista de la Academia $N^{\circ} 15$, LOM, Santiago.

INJUV (2006), Encuesta Nacional de Juventud 2005, Instituto Nacional de la Juventud, Santiago.

Mayol A. (2012), No al Lucro: de la crisis del modelo a la nueva era política, Debate, Santiago.

PNUD (2012), Desarrollo Humano en Chile, Bienestar subjetivo: el desafío de repensar el desarrollo, Santiago.

Romano V. (1993), Desarrollo y Progreso, Teide, Barcelona.

Salinas M. (2012), “Acerca de los cambios en la institucionalidad del Ejecu- 
tivo para la Seguridad Pública”, Corporación Ciudadanía y Justicia, Santiago.

SENAME, Anuario Estadístico Institucional de SENAME, años 2010 y 2013.

Simon J. (2012), Gobernar a Través del Delito, Gedisa, Madrid.

TMS. Programa Terapia Multisistémica (2014). Departamento de Reinserción Social. Subsecretaría de Prevención del Delito, Ministerio del Interior y Seguridad Pública. Santiago.

Van Dijk T. (2003), Ideología y Discurso, Ariel Lingüística, Barcelona.

Ídem (1990), La Noticia como Discurso. Comprensión, estructura y producción de la información, Paidós Ibérica, Barcelona.

Wacquant L. (2000), Las Cárceles de la Miseria, Manantial, Buenos Aires.

Recibido: 11.07.16

Aceptado: 30.07 .16 